\title{
Mechanism of Health Protection: Historical and Legal Analysis
}

\author{
Elena V. Vorontsova ${ }^{1 *}$, and Andrey L. Vorontsov ${ }^{2}$ \\ ${ }^{1}$ Department of Financial Law, Constitutional, Civil and Administrative Proceedings FSBEI HE «South-West State University» \\ Kursk, Russia \\ ${ }^{2}$ Department of Administrative and Labor Law FSBEI HE «South-West State University» Kursk, Russia
}

\begin{abstract}
The article is devoted to the study of the peculiarities of the formation of health protection institutes in Russia and European countries. Their importance for the current state of health systems is analyzed from the standpoint of historical and socio-legal analysis. The authors note that the formation of an administrative mechanism for the prevention and control of diseases took place in Eastern and Western Europe throughout the Middle Ages and New Times. However, the turning point in the development of health care institutions in Russia and in Europe was the 18th century. Since that time, we can talk about the formation of health systems in the modern sense. According to the authors, the idea of the state responsibility for the health of its population, as well as the belief of European scientists about the social nature of many diseases, which spread in Western Europe, contributed to this formation. In the authors' opinion, this fact led to the emergence of the first health laws, in which the main factor in the health of citizens was recognized as an improvement in their living conditions. It is noted that international recognition of health as a subjective right of every person has led to revolutionary changes in national health systems. National health standards began to change in the direction of their compliance with international standards. According to the authors, there are legal prerequisites for the formation of an effective and socially-oriented health care system in Russia. The authors think that there are legal prerequisites for the formation of an effective and socially-directed health care system in Russia. This is due to the constitutional consolidation of the right to health protection, as well as the treatment of health in its international legal significance. The main methods used were the method of analysis, the rationale, the comparative-historical method.
\end{abstract}

\section{Introduction}

Health is a necessary condition for the biological existence of man, a condition for the person to realize his opportunities in society, a condition that determines the very quality of life. The importance of health has never been questioned, but attitudes have been different, as there are possibilities for its preservation and strengthening. At the same time, humanity early realized the interdependence of the health of an individual and the health of the whole society, which did not allow considering it as an exclusively personal matter for everyone. Hence, the society quite objectively had a need for organized measures aimed initially at preventing and spreading infectious diseases, and then incidence in general. There was a need to create a social institution for health protection, which is now commonly called the health care system.

In each country, this system developed in its own way. However, there were general trends that ultimately led to the view that it was necessary to develop common approaches to health. The most striking expression of this position was the recognition of health as a human right, legally protected by both a separate state and the entire world community. However, the mechanisms of such protection, as well as the system directly providing health, differ significantly among countries. This is largely due to the peculiarities of the formation of national health systems, medical and legal traditions, differences in views on the health phenomenon itself.

In this article we will analyze the formation of health care institutions in Russia and the rest of Europe and assess the degree of compliance of the Russian health system with generally recognized international standards from the standpoint of constitutional consolidation of the provisions on the right to health.

\section{The history of the formation of the healthcare institutions in Russia and abroad}

An analysis of the formation of state institutions for health protection is impossible without resorting to the

\footnotetext{
* Corresponding author: proskyrinae@mail.ru
} 
history of healthcare as a special activity of society and the state. Throughout the development of human civilization, the idea of the need for organized measures to ensure public sanitation as the main factor in ensuring public health was evident. The evidence that measures to maintain the proper level of hygiene have been the usual practice of a state-organized society since ancient times is confirmed by numerous archaeological evidences. High-level water and sewerage systems found on the sites of the ancient cities of India, Egypt, Crete, the ancient Greek cities of Asia Minor, and the Inca and Aztec cities of South and Central America are the striking evidence of large-scale measures to maintain public sanitation and hygiene.

The cultural decline of the middle ages has undoubtedly affected the level of public sanitation (especially in Western Europe). Nevertheless, the general trend to maintain organized measures to combat insanitary conditions continued. As the authoritative expert in the field of public health history, G. Rosen, testifies, an important achievement of the middle ages was the creation of an administrative system dealing with the prevention of diseases, the supervision of sanitation and public health protection, which existed practically unchanged until the 19th century [1].

As for Russia, the formation of public health institutions here had its own peculiarities. At the same time, it should be noted that initially (in the preMongolian period) the public health protection system was in many ways similar to Western European models. This can be explained by a single set of Christian values that existed in Russia and in Europe before the 18th century, which respectively determined a unified approach to the organization of state power in general and in the field of health in particular. Among the Russian features of the functioning of the mechanism of health protection in this period can be called the existence of three separate types of public health (types of medical care). Such independent kinds were folk medicine (as a set of isolated methods of treatment, traditional views on the causes and consequences of diseases, etc.), monastic medicine, and also arose somewhat later on the basis of the two previous secular medicine.

The regulation of traditional medicine was originally based on pagan traditions. A great role was played by the widespread belief among the people in supernatural forces.

The adoption of Christianity and the increasing role of the Church influenced the formation of monastic medicine, in which the centres of accumulation of medical knowledge and medical care became monasteries.

The first attempt at regulatory regulation of medical activities in Russia (Ancient Rus) occurs at the stage of the formation of monastic medicine. The "Church Charter" of Prince Vladimir, as well as "Russian Pravda" as the main source of Old Russian law enshrined the obligation of monasteries to maintain hospitals, and also provided for the possibility of providing medical care at home on a reimbursable basis. At the same time, the doctors of the monastery hospitals had the status of "people of the church" who provided their help free of charge, guided by Christian morality. The provision of the same help outside the monastery walls by the norms of church law was not regulated, which gives us the right to view this activity as secular medicine.

The peculiarity of Russia was the formation of state medicine in comparison with Europe. In our country, it began to be formed in the 16th century with the formation of the Pharmacy Order - the first organ of centralized management of the medical case. It should be noted that the state medicine in Russia developed as exclusively secular, with the active use of foreign physicians.

The 18th century was a turning point in the development of the healthcare system in Russia and the rest of Europe. From this time we can talk about the emergence of the institution of health protection in the proper sense of the word. Unlike most European countries, where the regulatory regulation of medical activities was carried out mainly by medical professional corporations, in Russia the state took the initiative of legal regulation of medical activities. Moreover, this process had a clearly expressed militarized character, since the formed medical cadres and organizational infrastructure provided primarily the needs of the army and navy. Created with the direct participation of Peter I Military (1716) and Marine (1720), the Statutes determined the requirements not only for the professional activity of doctors, but also for their personal qualities [2].

A major role in the formation of the state Institute of health protection in Russia was played by the Senate Decree of 1721, which banned the implementation of medical activities without special permission of the pharmacy (since 1725 - Medical) office - the main body of state management of medical Affairs in Russia [3]. A general comprehensive legal document that defined the organizational and staff structure of hospitals, the duties of officials, the procedure for medical examination of patients and the training of physicians (auxiliary medical personnel) was the "General Regulations on Hospitals and the Posts of Doctors and Other Medical Employees Who Worked in them" in 1735, which significantly improved the process of providing medical care in Russian hospitals.

It should be noted that in Western Europe at this time public health was not organized at such high level. In many respects this was due to the initially different ways of developing medical care for the population in Europe and in Russia. In Europe, medical activities were privatelegal (that is, carried out by private practitioners), in Russia, medical care since the time of the formation of the empire was a state affair; was of a public nature. Both systems of medical care had their pros and cons. The drawback of the Russian system was insufficient attention to health issues of the civilian population (due to the focus on the needs of medical care for the state apparatus, army and navy). The first attempts to provide the civilian population with medical care were made in Russia only in the middle of the 18th century. These attempts consisted in entrusting the city authorities with the obligation to provide apartments and money for 
doctors who had completed their medical work in the army.

It is necessary to recognize the priority precisely in conceptual comprehension of the social importance of health for Europe. At the end of the 18th century, the Germans were at the forefront of these ideas. The opinion about the responsibility of the monarch for the health of his people was influenced by the philosophy of enlightened absolutism precisely in Germany [4, 1]. It was the Germans who first created the so-called medical police that monitored the observance of sanitary and hygienic conditions in the cities. This structure has spread to other countries and throughout the 19th century quite successfully coped with its functions in major cities in not only Western Europe, but also the USA [5].

For the European scientific and medical thought of that period, it was characteristic to understand the problems of health and public health in the social aspect, i.e. from the standpoint of the analysis of the social causes of the disease. Outstanding Austrian physician and public figure J.P. Frank in 1790 declared, "it is necessary that the government eradicate poverty in our areas, which most of all generates any disease" [6, 7]. As can be inferred from his words, even at the end of the 18 th century, among the advanced circles of European doctors, a conviction was expressed about the social nature of many diseases and the need to improve the living conditions of the population for their eradication.

This time also includes an attempt to draw attention to health problems at the international level. The J.P. Frank, in his work "Epistola Invitatoria ad Eruditos" (an invitation to scientists), outlined the need for international participation in the regulation of public health issues and insisted on the exchange of information on health among states $[8,1]$. At this time, in the works of French educators, more attention is paid to the need to educate people about health issues. At the same time, certain attention was paid to the responsibility of the state for the health of its citizens, in particular, the need for supreme power (an enlightened monarch) to combat child mortality and socially support the population. One of the most prominent representatives of French education, D. Diderot, considered in his extreme views even the introduction of pensions and compulsory medical care for the elderly population [9].

The European industrial revolution of the 19th century played a huge role in shaping the modern healthcare system. New problems in public health caused by industrial development were forced to undertake reforms to ensure urban sanitation. The pioneers in the creation of a new public health system were the British, because in England these problems were most acute (it is enough to recall the major epidemics of cholera in 1832 and 1849). The Law on the Poor in 1834 started the new system. On the basis of this law in the UK began to operate the Commission on the poor, which was engaged in the analysis of the causes of disease among the working population. This Commission has established a clear link between the sanitary condition of the citizens' living environment and their state of health [1, 10, and 11]. The British public health Act, adopted in 1848, was largely the result of the Commission's activities. This
Act provided for the creation of a centralized system of health departments [1, 12] primarily concerned with ensuring basic health preconditions for health: clean water, the availability of sewerage, and so on.

It should be noted that at this time in Russia, which was the ancestor of the public health system, there is a reverse process. Only at the beginning of the 19th century city doctors were appointed to large cities, and in General medical care of the civilian population sought to transfer the responsibility of local authorities, which was done with the establishment of Zemstvos in 1864.

Thus, attempts to create institutions of health care, responsible for its state of the population have been made for many centuries. The result was the first health laws adopted in the 19th century. They served as the basis for the creation of a modern healthcare system throughout the world. At the same time, it should be remembered that this system became really effective and socially-oriented only in the 20th century, with the recognition of health as a human right.

\section{International and national health protection mechanisms}

The 20th century was marked by the active creation of interstate and international mechanisms for protecting the health of citizens. There is no doubt that, first of all, this process was provoked by recognition in the international community of health and its protection as a subjective right of any person. At the same time, it should be noted that international and national mechanisms for health protection have been developed in many ways in parallel, which are interdependent and mutually complementary.

In the context of the consideration of the formation and legal support of international and national mechanisms for health protection, one important feature should be noted, which, in our view, largely determines the functioning of these mechanisms at the present time. The fact is that sanitary, quarantine and other state measures aimed at ensuring public health in the historical retrospect began to be implemented and achieved significant development much earlier than those or other human rights, including the right to health, received it recognition. Hence, the mechanism of health protection, and its corresponding legal support, has long been developed without taking into account the rights of individual. All international agreements on health issues, as well as the laws of individual states until the middle of the 20th century, were purely public-legal. Only with the signing of the Charter of the World Health Organization (WHO) on July 22, 1946, the preamble of which proclaimed the right to "the maximum possible level of physical, intellectual and social well-being", the process of securing the right to health as the individual right of every person began.

Currently, the norms of international and national health law provide for the right of private persons in this sphere of public relations, and accordingly corresponding duties of the state. At the same time, it should be noted that the multifaceted aspects of the 
implementation of the "fundamental human right in the field of health" (in this formulation the right to health is designated as an object of research in the majority of scientific and theoretical works of Russian scientists), the differences in socio-economic and other conditions affecting on the health of a person in a particular country (including significant differences in health systems), do not allow the adoption of a single concept ensuring the implementation of this right. Both in Russia and in other countries, state authorities are trying to limit their health responsibilities, but the activity of civil society often encourages governments of these countries to meet the requirements in the field of health, enshrined in international acts. Such acts include: the 1948 Universal Declaration of Human Rights, the 1966 International Covenant on Economic, Social and Cultural Rights, the 1966 International Covenant on Civil and Political Rights, the Declaration on the Rights of Mentally Retarded Persons of 20 December 1971, the Declaration on the Rights of Persons with Disabilities of 9 December 1975, the Convention on the Elimination of All Forms of Discrimination against Women of 18 December 1979, the Convention on the Rights of the Child of 20 November 1989, the Alma-Ata Declaration on Primary Health Care, 1978.

In the legal sense, the above-mentioned documents impose on the signatory countries a certain range of legal obligations, which may involve the adoption of all necessary measures for the implementation of the rights enshrined in these acts. These measures, as appropriate, may involve changes in existing national legislation and administrative practices. At the same time, the "crosscutting" duty of all states that have acceded to these acts is to ensure the rights enshrined therein, at least to a minimum. This minimum level is usually expressed in a very concrete way, and its achievement is mandatory for states, regardless of their degree of economic development.

Let us note that the international acts we have listed earlier have a universal character, which is an additional incentive for States to use mechanisms to ensure the rights enshrined in them, including the right to health.

In addition to acts of a universal nature, there is a whole set of regional international acts that regulate the "fundamental right in the field of health" within the European Union, the Commonwealth of Independent States, the Council of Europe and other international organizations and unions. Such acts include the European Convention for the Protection of Rights and Fundamental Freedoms (1950), the European Social Charter (revised from May 3, 1996), the CIS Convention on Human Rights and Fundamental Freedoms of May 26,1995 , and a number of others. Their main target is to guarantee the access of citizens of different countries to the health care system, which should be financed primarily from the state budget (the European Committee for Social Rights put forward a funding requirement). In turn, such a health care system should include: a public system that allows to provide the necessary medical care to the entire population and provides prevention and diagnosis of diseases; special measures to protect the health of mothers, children and the elderly; general measures aimed at combating alcoholism and drug addiction, control of food quality and the state of the environment [13].

We note with regret that access to health services as an individual right is not now universally recognized. In our opinion, the main reason for this is the difficulty of securing such right by the state, as it entails large financial costs on its part. Moreover these costs are not limited only to the costs of providing medical care; they include financing of many social issues: adequate nutrition, sanitation, provision of adequate housing, work, etc. There is the whole complex of living conditions, which are called "social well-being".

As for Russia, our country fully embraced this approach in the organizing of its own healthcare system. The right to health protection (this is a formulation in the Russian Federation that the internationally recognized "right to health", since Russia believes that only health protection as a set of measures, and not health as such, can be legally guaranteed by the state) has a constitutional status in Russia (Article 41 of the Constitution of the Russian Federation). In addition, the Russian Constitution contains a specific provision that medical care in state and municipal health institutions is provided to citizens free of charge at the expense of the relevant budgets, insurance premiums and other revenues (part 1 of article 41 of the Constitution of the Russian Federation). Part 2 of Article 41 of the Constitution of the Russian Federation establishes the obligation of the state to finance programs for the protection and promotion of public health, and strengthening of health of the population, and also to promote the activity promoting development of physical culture and sports, ecological and sanitary and epidemiological well-being. Moreover, the protection of labour and health of people, state support for the family, motherhood, paternity and childhood, their social protection - are one of the foundations of the constitutional system of Russia (Article 7 of the Constitution of the Russian Federation).

In the context of the creation of an "adequate healthcare system" in Russia, the definition of the very concept of health protection, contained in the Federal Law No. 323-FZ of 21.11.2011 "On the fundamentals of protecting the health of citizens in the Russian Federation" is of no interest. According to this law, health protection is a system of measures of political, economic, legal, social, scientific, medical, including sanitary and anti-epidemic (preventive) nature, carried out by state authorities of the Russian Federation, state authorities of the subjects of the Russian Federation, local authorities self-government, organizations, their officials and other persons, citizens in order to prevent diseases, preserve and strengthen physical and mental health of each person maintaining its long and active life, providing one with medical assistance (Art. 2 of the Federal Law "On the basis of public health protection in the Russian Federation"). The authors of this study believe that such legislative formulation is most consistent with the spirit of the fundamental international legal acts in the field of health. Based on this, it can be argued that at present the Russian Federation has a 
sufficient legal basis for creating an effective health care system. The state should only follow the principles proclaimed by it and use the available resources for the intended purpose.

\section{Conclusion}

Our research work allowed us to draw the following conclusions:

1. Throughout the development of human civilization, health was perceived as one of the most important values. In this regard, it was obvious that there was a need for organized state measures to ensure the health of the population. Numerous archaeological evidences show that the maintenance of sanitation and hygiene has been a common practice of state-organized society since ancient times.

2. Throughout the middle Ages and Modern times, an administrative mechanism for disease prevention, sanitation and public health care has been established in Eastern and Western Europe. Attempts were made to regulate medical activities. In Russia and Europe, the process of establishing health care institutions had its own characteristics, but the general trend was to maintain organized measures to combat diseases.

3. The turning point in the development of health care institutions in Russia and in Europe was the 18th century. Since then we can talk about the folding of health systems in the modern sense. This was promoted by the humanistic idea spreading in Western Europe about the responsibility of the state for the health of its people. At the same time, the conviction about the social character of many diseases began to spread, which led to the appearance of the first health laws providing for the improvement of living conditions of citizens as the main factor of their health.

4. The recognition of health as a subjective right of everyone has led to revolutionary changes in the health systems of most countries. The consolidation of this right in the most important international legal acts led to the formation of an international mechanism for the protection of public health in the person of WHO, the UN Human Rights Council, the European Committee on Social Rights and other organizations. In turn, this caused states to change their national health standards in the direction of their greater compliance with international standards. At the same time, the multifaceted aspects of the realization of the right to health, the differences in the socioeconomic and other conditions of states, significant differences in health systems, do not allow us to adopt a single concept that ensures the realization of this right.

5. Russia is one of those countries where the right to health protection is enshrined at the level of the Constitution. This creates the conditions for the formation of an effective and socially-oriented health care system in our country. At the same time, the Russian legislator stands on the position of impossibility of legal guarantee of health as a subjective state, depending on a variety of reasons, including having a personal character. That is why the Russian Federation guarantees "the right to health protection" as a set of measures provided by the state, and not the "right to health", which, according to Russian lawyers, cannot be provided to everyone.

\section{References}

1. G. Rosen, A History of Public Health, Expanded Edition, 535 (Baltimore and London: The Johns Hopkins University Press, 1993)

2. L.L. Khundanov, Meditation of the doctor, 160 (1983)

3. V.L. Popov, N.P. Popova, Legal basis of medical activity. Reference and information guide. 256 (1999)

4. H.E. Sigerist, Medicine and Human Welfare. 164 (New Haven / London: Yale University Press / Oxford University Press, 1941)

5. A. de. Swaan, In Care of the State: Health Care, Education and Welfare in Europe and the USA in the Modern Era, 339 (Cambridge, Polity Press in association with Basil Blackwell, 1988)

6. Speech I.P. Frank, 1790 "Human poverty: the mother of all diseases." 1941

7. B. Tobes, The right to health: theory and practice: Per. with English. 348 (2001)

8. J.P. Frank, Epistola Invitatoria ad Eruditos, 23 (1776)

9. D. Diderot, Encyclopedie on dictionnaire raisonne des sciences des arts el des métiers (Articel «Hospital», Stuttgart/Bad Cannstatt: Frommann. 1967)

10. E. Chadwick, Report on the Sanitary Condition of the Labouring Population of Great Britain, 1842, 452 (Edinburgh University Press; Later Edition edition (1 Jan. 1984)

11. The First Ten Years of the World Health Organization. Geneva: World Health Organization. 538 (1958)

12. R. Roemer, The Right to Health Care in: Pan American Health Organization. 17-27 (The Right to Health in the Americas, Washington: PAHO. 1989)

13. D. Gomien, D. Harris, L. Zwaak, European Convention on Human Rights and the European Social Charter: Law and Practice. 516 (1998) 